\title{
Significance and management of acetic acid bacteria culture collections
}

\author{
Luciana De Vero, Paolo Giudici \\ Department of Life Sciences, University of Modena and Reggio Emilia, Reggio Emilia, Italy
}

\begin{abstract}
Acetic acid bacteria (AAB) are obligate aerobic microorganisms which have large significance in human life. Traditionally, AAB species have been used to produce fermented food and beverages thanks to their ability to oxidize ethanol to acetic acid. Moreover, in the last decades, they have been extensively investigated for other industrial biotechnology applications as the development of processes for highvalue products or biosensors. The potential exploitation of AAB diversity requires the existence of microbial culture collections, which are able to supply not only strains but essential data for fundamental microbial research. Therefore, microbial collections can be helpful to provide critical insights into AAB physiology and metabolism as well as integrate sequence data with transcriptional and functional studies to better define complex traits and develop new potential microbial processes.
\end{abstract}

Correspondence: Luciana De Vero, Department of Life Sciences, University of Modena and Reggio Emilia, via Amendola, 2 - Pad. Besta - 42122 Reggio Emilia, Italy.

Tel. +39.0522.522057 - Fax: +39.0522 .522027 .

E-mail: luciana.devero@unimore.it.

Key words: acetic acid bacteria, culture collections, Biological Resource Centers.

Acknowledgments: a transnational access for a study visit to CABI Microbial Service (Egham, Surrey, UK) has been granted to Luciana De Vero from the European Community's Seventh Framework Programme (FP7, 2007-2013), Research Infrastructures action, under the grant agreement No. FP7-228310 (EMbaRC project). She is grateful to Dr David Smith, Director of Biological Resources, CABIs Microbial Services division, for the great and useful opportunity and to Dr Matthew Ryan, Curator of CABI Genetic Resources Collection, for the technical training and useful comments on the manuscript.

Conference presentation: part of this paper was presented at the $3^{r d}$ International Conference on Acetic Acid Bacteria. Vinegar and Other products, 2012 Apr 17-20, Cordoba, Spain (http://www.uco.es/aab2012/).

Conflict of interests: the authors declare no potential conflict of interests.

Received for publication: 12 October 2012.

Revision received: 24 December 2012.

Accepted for publication: 25 January 2013.

This work is licensed under a Creative Commons Attribution 3.0 License (by-nc 3.0).

(C) Copyright L. De Vero and P. Giudici., 2013

Licensee PAGEPress, Italy

Acetic Acid Bacteria 2013; 2(s1):e9

doi:10.4081/aab.2013.s1.e9
This article reviews the significance of microbial collections, with an overview of the well-known European Biological Resources Centers (BRCs) collecting AAB, and provides an insight into their cultivability and metabolic activity. It also discusses appropriate techniques in preserving authentic strains, quality control implications, databases and BRC networking as well as connections among collections and stakeholders.

\section{Introduction}

Microbial culture collections are fundamental biological resource centers able to supply more than just strains but essential data related to the genome, transcriptome, proteome and metabolome of the microorganisms collected. In a few words, culture collections hold biological material and related information, the first is meaningless without the second. They can offer services helpful for several purposes such as research, teaching, screening assay, knowledge-based bioeconomy as well as biotechnological applications. Generally, microbial collections have the crucial role to maintain and provide the authenticated biological material which can include microorganisms as well as associated genomic materials (e.g. purified DNA, DNA sequences, cloned genes, plasmids and vectors). Additionally they maintain microorganisms cited in scientific papers that can be used for further study, can serve as repositories for strains as patent deposits and providers of safe and confidential services to store key organisms for research and industry. ${ }^{1}$

The demands upon microbial collections can be different according to the type of microorganisms collected and their metabolic potential. Certainly culture collections and biotechnology are strongly connected, since the microorganisms maintained by them can be used as biocatalysts or sources of compounds with great relevance in research and industry. Furthermore, microbial collections have greatly contributed to the development of many techniques over time, such as cell culturing, recombinant DNA, polymerase chain reaction (PCR) techniques, DNA shuffling, site-directed mutagenesis, metabolic engineering and artificial enzyme synthesis, since they supply the biological tools for biochemists and molecular biologists. ${ }^{2}$

Acetic acid bacteria (AAB) are a group of aerobic microorganisms, with 13 genera actually recognized (Acetobacter, Acidomonas, Ameyamaea, Asaia, Gluconacetobacter, Gluconobacter, Granulibacter, Kozakia, Neoasaia, Neokomagataea, Saccharibacter, Swaminathania, Tanticharoenia), as reported in the List of Prokaryotic names with Standing in Nomenclature (http://www.bacterio.cict.fr Accessed 2012 July 6), which have large significance in human life. Traditionally, AAB strains have been utilized to produce fermented food and beverages, especially several kinds of vinegar, thanks to their ability to oxidize ethanol to acetic acid. Moreover, due to their metabolic uniqueness, they have been extensively investigated for production of high-value chemical products for biopharmaceutical industry. Nevertheless new insight on $\mathrm{AAB}$ has been recently gained in relation to the existence of some species associated with human diseases..$^{3-5}$ 
The potential exploitation of AAB strain diversity requires the existence of culture collections, where successful cultivation methods as well as appropriate tools in preserving authentic strains are screened in order to overcome the greatest hurdles related to $\mathrm{AAB}$ growth in laboratory conditions. Nowadays there is a huge number of culture collections around the world. The World Data Centre for Microorganisms (WDCM; http://www.wfcc.info/ccinfo/statistics Accessed 2012 July 20) reports more than 2 million strains of a wide range of microorganisms maintained in 622 culture collection centers in 71 countries. Many public service collections have evolved into Biological Researches Centers (BRCs) which hold subcultures of original strains and guarantee accessibility and transparency of supply, according to all relevant regulations required by the Convention on Biological Diversity (CBD). ${ }^{6}$

The majority of $\mathrm{AAB}$ strains are maintained in well-known microbial collections established in different countries such as: the American Type Culture Collection (ATCC) in USA, the Biotec Culture Collection (BCC) in Thailand, the National Collection of Industrial Microorganisms (NCIM) in India, the Korean Collection for Type Cultures (KCTC) in Korea, the Japan Collection of Microorganisms (JCM) and the NITE Biological Resource Center (NBRC) in Japan. Considering just the European scenario, AAB strains are held in a relatively small number of BRCs (Table 1). Moreover, AAB strains are also kept in other collections some of them non-affiliated in official organizations, including those at universities, research institutes or companies, where knowledge of their existence is mainly due to publications, conferences or just personal contacts. These collections have usually been gathered for special purposes or specific project and sometimes they are strictly dependent on research targets, resources and facilities as well as specific interests of the scientists involved.

Among these, the Food and Industrial Microbial (FIM) Collection of the Department of Life Sciences, University of Modena and Reggio Emilia, was established in 1999. It has improved over time through the activities of the food microbiology group, aiming to maintain and supply acetic acid bacteria, lactic acid bacteria and yeast strains for research as well as implementing linkages between academia and companies. Currently, FIM Collection holds about three thousands strains isolated from several matrices and, specific to this collection are about $300 \mathrm{AAB}$ strains isolated from musts, wines, different kinds of vinegar and kombucha tea. ${ }^{7-9}$

\section{Cultivability and metabolic activity of acetic acid bacteria}

Several AAB are able to entry into a viable but non-cultivable status ${ }^{10,11}$ and a task for microbial collections is to overcome drawbacks related to difficulties in cultivation and the validation of appropriate methodology for maintenance of the cultures. Actually, several media, mostly consisting of the same ingredients differently proportioned, have been developed and tested to obtain successful isolation of different $\mathrm{AAB}$ from specific matrices as they can have different requirements from one strain to another. For instance GYC medium (10\% glucose, $1 \%$ yeast extract, $2 \% \mathrm{CaCO}_{3}$ ) has been successful used for recovering of osmotolerant AAB strains from high sugar sources such as traditional balsamic vinegar. ${ }^{7}$ Moreover media with the addition of acetic acid and ethanol as $\mathrm{AE}(0.5 \%$ glucose, $0.3 \%$ yeast extract, $0.4 \%$ peptone, $3 \%$ (v/v) absolute ethanol, $3 \%$ (v/v) glacial acetic acid) and RAE (4\% glucose, $1 \%$ yeast extract, $1 \%$ peptone, $0.338 \% \mathrm{Na}_{2} \mathrm{HPO}_{4} \times \mathrm{H} 20,0.15 \%$ citric acid, $2 \%$ (v/v) ethanol, $1 \%$ (v/v) acetic acid) are particularly recommended for the cultivation of strains isolated from spirit vinegar fermentations which are able to produce high acetic acid concentration up to $15 \% .12,13$ However these media containing ethanol are not suitable for preservation as it can affect the viability of cells during long-time storage at $+4^{\circ} \mathrm{C} .{ }^{14}$ Culture collection databases generally report the recommended media for cultivation of strains as well as the specific incubation conditions. In Table 2 the main culture media have been described according to recipes indicated in online databases of the European BRCs col-

Table 1. European Biological Resources Centers collecting acetic acid bacteria.

\begin{tabular}{|c|c|c|c|}
\hline Acronym & Name & Country & Website URL \\
\hline CIP & Collection de l'Institut Pasteur & France & http://www.crbip.pasteur.fr \\
\hline BCCM/LMG & Belgian Coordinated Collections of Microorganisms/LMG Bacteria Collection & Belgium & http://bccm.belspo.be/index.php \\
\hline CECT & Colección Española De Cultivos Tipo & Spain & http://www.cect.org \\
\hline DSMZ & Deutsche Sammlung von. Mikroorganismen und Zellkulturen GmbH & Germany & http://www.dsmz.de/ \\
\hline NCCB & Netherlands Culture Collection of Bacteria & Netherlands & http://www.cbs.knaw.nl/nccb \\
\hline NCIMB & National Collection of Industrial, food and Marine Bacteria & United Kingdom & http://www.ncimb.co.uk \\
\hline VTTCC & VTT Culture Collection & Finland & http://culturecollection.vtt.fi/ \\
\hline
\end{tabular}

Table 2. Main culture media for acetic acid bacteria growth.

\begin{tabular}{|c|c|c|c|c|c|c|c|}
\hline Components (g)* & $\mathbf{A G}$ & GY (1) & GY (2) & GYC (1) & GYC (2) & YPG & YPM \\
\hline Glucose & 1.0 & 50 & 20 & 100.0 & 50 & 70 & - \\
\hline Yeast extract & 5.0 & 5 & 10 & 10.0 & 10 & 10 & 5.0 \\
\hline Peptone & 5.0 & - & - & - & - & 10 & 3.0 \\
\hline $\mathrm{CaCO} 3$ & 7.0 & - & - & 20.0 & 30.0 & - & - \\
\hline Mannitol & - & - & - & - & - & - & 25.0 \\
\hline Glycerol & 1.5 & - & - & - & - & - & - \\
\hline Malt extract & 2.0 & - & - & - & - & - & - \\
\hline Agar & 15.0 & 15.0 & 15.0 & 15.0 & 15.0 & 15.0 & 15.0 \\
\hline Distilled water (mL) & 1000 & 1000 & 1000 & 1000.0 & 1000 & 1000 & 1000.0 \\
\hline $\mathrm{pH}$ & 6.8 & 6.5 & / & 6.8 & I & 6.0 & / \\
\hline
\end{tabular}

*According to culture media recipes reported in online databases of the European Biological Resources Centers collecting acetic acid bacteria (see Table 1 for the websites). Accessed 2012 July 6. 
lecting $\mathrm{AAB}$. Important strains are required to be deposit in different collections and more than one medium can be suggested for their recovery and subculturing; an example for the AAB strains, referred to as type species, has been reported in Table 3 .

A common metabolic activity to AAB is the incomplete oxidation of alcohols or sugars. Most of them, except Asaia sp., are capable of oxidising ethanol to acetic acid, however Saccharibacter sp. and Granulibacter sp. may produce only negligible or very little acetic acid from ethanol. Furthermore, some AAB are able to carry out the oxidation of acetic acid to $\mathrm{CO}_{2}$ and $\mathrm{H}_{2} \mathrm{O}$. Specifically, the overoxidation of acetic acid is a feature of Acetobacter (A.), Gluconacetobacter ( $G a$.) and Acidomonas strains whereas it is lacking in Gluconobacter $(G$.), Saccharibacter and Neoasaia and weak in Asaia, Kozakia, Swamina thania, and Granulibacter. ${ }^{15}$

Different AAB strains show variation in their metabolism of individual carbohydrates, but those most preferentially used are glucose, galactose, mannose, ribose, xylose, arabinose, erythritol, mannitol, and sorbitol. ${ }^{16}$ Species of Acetobacter and Gluconobacter lack a functional Embden-Meyerhof Parnas pathway and, consequently, are unable to metabolize hexose sugars by this route. ${ }^{17}$ Hexose and pentose sugars, after initial phosphorylation, are oxidatively metabolized by the hexose monophosphate pathway to acetic and lactic acids which, in the case of Acetobacter species, can be further oxidized to carbon dioxide and water via the tricarboxylic acid cycle. The carbohydrate metabolism of G. oxydans has been extensively investigated since its incomplete oxidation of various sugars and sugar alcohols leads to the accumulation of industrially significant substances, such as sorbose, dihydroxyacetone, gluconic acid and ketogluconic acids in the culture medium. ${ }^{17-20}$

Two types of enzyme systems, which differ in location and function within the cell, are capable of dehydrogenation reactions, ${ }^{21}$ consequently sugars, alcohols and polyols are oxidized via two alternative pathways. ${ }^{16}$ The first type of enzyme systems involve dehydrogenases located in the cytoplasmic membrane that catalyze the nonphosphoryla- tive oxidation of sugars, polyols, aliphatic and cyclic alcohols to almost quantitative yields of oxidation products which are easily released into the medium via porines in the outer membrane..$^{21,22}$

The second type of enzyme systems is characterized by NAD(P) ${ }^{+}$ dependent enzymes, which are believed to participate in the synthesis of biosynthetic precursors and are involved in the maintenance of cells in the stationary growth phase. ${ }^{21}$ The substrate oxidized and the resulting intermediates are phosphorylated and further metabolized via the pentose phosphate pathway. ${ }^{20}$

\section{Preservation techniques and quality control: implica- tions and strategies}

$\mathrm{AAB}$ preservation in culture collections has the primary purpose to maintain them in a viable state without morphological, physiological or genetic change. Nevertheless, marked genetic instability has been observed in these bacteria, which causes spontaneous mutations at high frequencies leading to deficiencies in various physiological properties, such as acetic acid resistance and ethanol oxidation. ${ }^{23}$ An insertion sequence element, IS1380, was identified as a major factor of the genetic instability, which causes insertional inactivation of the gene encoding cytochrome $\mathrm{c}$, an essential component of the functional alcohol dehydrogenase complex. ${ }^{24}$ In addition, an insertion sequence, named IS1452, in the ADH subunit III ( $a d h S$ ) gene was found to cause mutations at high frequencies in spontaneous A. pasteurianus mutants, deficient in ethanol oxidation. ${ }^{25}$ Despite genetic background of the $A A B$ instability is still not well investigated, it has significant influence on industrial use of these microorganisms. Due to the existence of hypermutable $\mathrm{AAB}$ isolated from nature, ${ }^{26}$ continuous growth techniques are not recommended for preservation but mainly used just for short-term maintenance of the strains. In fact these techniques, which initially provide optimum growth conditions and involve frequent transfer from depleted to fresh nutrient sources, usually allow deterioration and loss of properties during storage. ${ }^{27}$ Long-term maintenance of the strains

Table 3. Strains referred to as type species of AAB collected by European Culture Collections.

\begin{tabular}{|c|c|c|}
\hline Species & Type species* & Recommended culture media \\
\hline A. aceti & $\begin{array}{l}\text { NCIMB } 8621 \\
\text { CIP 103111/DSM } 3508 \\
\text { CECT 298/VTT E-011873/NTT E-042567/VTT E-97828 } \\
\text { LMG 1261/ LMG } 1504 \\
\text { NCCB 23001 }\end{array}$ & $\begin{array}{l}\text { GY (2), GYC (2) } \\
\text { YPM } \\
\text { GYC (1), YPM } \\
\text { GYC (2), YPM } \\
\text { YPM }\end{array}$ \\
\hline G. oxydans & $\begin{array}{l}\text { NCCB } 23002 / \text { NCCB } 75005 \\
\text { NCIMB } 9013 \\
\text { VTT E-89365 } \\
\text { LMG } 1408 \\
\text { CIP 103106/VTT E-97864/DSM 3503/ DSM } 7145\end{array}$ & $\begin{array}{l}\text { GYC (2) } \\
\text { GY (2), GYC (2) } \\
\text { GYC (1), YPM } \\
\text { GYC (2), YPM } \\
\text { YPM }\end{array}$ \\
\hline Ga. liquefaciens & $\begin{array}{l}\text { NCIMB } 9136 \\
\text { DSM } 5603 \\
\text { CIP } 103109 \\
\text { LMG 1381/ LMG 1382/ NCIMB } 9136\end{array}$ & $\begin{array}{l}\text { GY (2), GYC (2) } \\
\text { GYC (1), YPM } \\
\text { YPM } \\
\text { GYC (2), YPM }\end{array}$ \\
\hline Sa. floricola & $\begin{array}{l}\text { LMG } 23170 \\
\text { DSM } 15669\end{array}$ & $\begin{array}{l}\text { GY (1) } \\
\text { YPG }\end{array}$ \\
\hline K. baliensis & $\begin{array}{l}\text { DSM } 14400 \\
\text { LMG } 21812\end{array}$ & $\begin{array}{l}\mathrm{AG} \\
\mathrm{GYC}(2)\end{array}$ \\
\hline Sw. salitolerans & LMG 21291 & YPM \\
\hline A. bogorensis & LMG 21650/ NCIMB 13692 & GYC (2) \\
\hline N. chiangnaiensis & LMG 24037 & YPM \\
\hline
\end{tabular}


can be achieved by techniques that are able to suspend the metabolism. Generally, these techniques involve reducing the water content available to cells by lyophilization (freeze-drying) or cryopreservation.

\section{Freeze-drying techniques}

Freeze-drying is one of the most widely used methods for long-term preservation of bacterial cultures and other microorganisms ${ }^{28}$ (Figure 1). It is a complex process that involves the removal of water from a frozen product by sublimation. ${ }^{29}$ The moisture remaining in freezedried cells is termed residual moisture. A residual moisture content of $1-3 \%(w / v)$ seems to be required for the long-term shelf life of bacteria. ${ }^{28}$ Freeze-drying is the preferred method for transporting and storing microbial cultures as it offers many advantages over other preservation techniques, including the total sealing of the specimen and protection from infection and infestation. Cultures generally have good viability/stability and can be stored for many years. Ampoules take up little space and can be easily stored.$^{27}$ However, the method shows also some disadvantages with some isolates which fail to survive the process or have reduced viability and may show genetic change..$^{30}$ Moreover cell damage can occur during the cooling and/or drying stages because of the phase changes that can disrupt the fluid-mosaic structure of the membrane. During these processes, in fact, the liquid crystalline structure of the cell membranes may degenerate to the gel phase, causing leakage of the membranes. ${ }^{27}$ To avoid this, suitable cryoprotectants, such as glycerol, dimethyl sulfoxide (DMS0), polyvinylpyrrolidone, skimmed milk, dextran, inositol, malt extract, mannitol, raffinose, sucrose and trehalose, have been tested at different concentrations to improve strain viability. The optimal cell concentration for freeze-drying is generally related to the protective medium used; usually, a cell concentration of $1 \times 10^{8}$ cells $\mathrm{mL}^{-1}$ can be considered appropriate, however, the higher the initial cell concentration, the longer viable cells will survive within the freeze dried sample. ${ }^{31}$

Several authors have evaluated the influence of cryoprotectans upon $\mathrm{AAB}$ survival during freeze-drying and subsequent storage when selecting a freeze-dried starter culture for vinegar making. ${ }^{12,32}$ Acetobacter strains were preserved by freeze-drying for about 1 year without any loss of their original properties as starter by using $20 \%$ malt extract during the lyophilization process. ${ }^{8}$ Nomura and co-workers ${ }^{33}$ prepared freeze-dried cells of $A$. aceti to use them as an additive for manufacturing and processing foods. They found that the addition of $30 \%$ sucrose to the cell suspension prepared in a Mcllvaine buffer $(\mathrm{pH} 6)$ before lyophilization was effective for preventing the decrease of the aldehyde oxidase activity during preparation and subsequent storage. Moreover, two thermoresistant AAB strains, belonging to A. senegalensis and $A$. pasteurianus were preserved by the freeze-drying process carried out using $20 \%$ mannitol (w/w) as cryoprotectant. Mannitol was determinant to enhance biomass preservation during storage, in fact, freezedried cells could be conserved at $4^{\circ} \mathrm{C}$ for at least 6 months without loss of viability. ${ }^{34}$ Unfortunately, a preservation method that is satisfactory for one strain may be unsuitable for others. Certainly, preservation protocols including cell growth conditions, suspension media, cryoprotectant, and cooling rates must all be optimized as the factors determining survival tend to be strain specific. ${ }^{35}$ Factors affecting survival are becoming better understood at the subcellular level, but many strains from a wide range of species remain difficult to preserve.

\section{Cryopreservation techniques}

When lyophilization is not amenable for suitable cell preservation, cryopreservation techniques can be considered valuable. Cryopreservation, usually, involves storage at temperatures of around $70^{\circ} \mathrm{C}$ in a mechanical freezer and, more advisable, at $-196^{\circ} \mathrm{C}$ in liquid or circa $-150^{\circ} \mathrm{C}$ in vapor phase of nitrogen ${ }^{28}$ (Figure 2).

Generally, vapor-phase storage is more convenient and safer for reg- ular access to stored material than liquid-phase storage. Furthermore, some manufacturers (e.g., CBS distributed by PhiTech Intl., Milton Keynes, UK) are now producing vapor-phase storage systems in which liquid nitrogen is retained in the vessel walls, which improves safety and appears to provide a temperature profile superior to standard vapor-phase systems. ${ }^{36}$

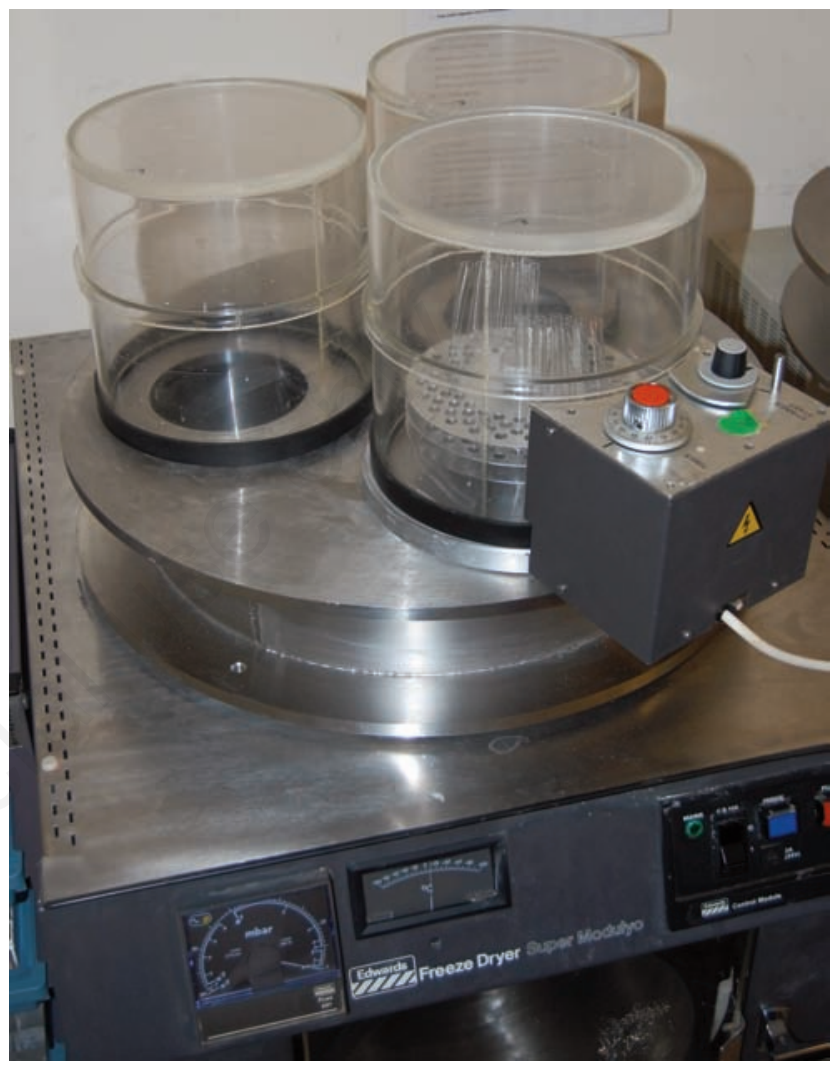

Figure 1. Freeze drying equipment [photo by kind permission of CABI Microbial Service (Egham, Surrey, UK)].

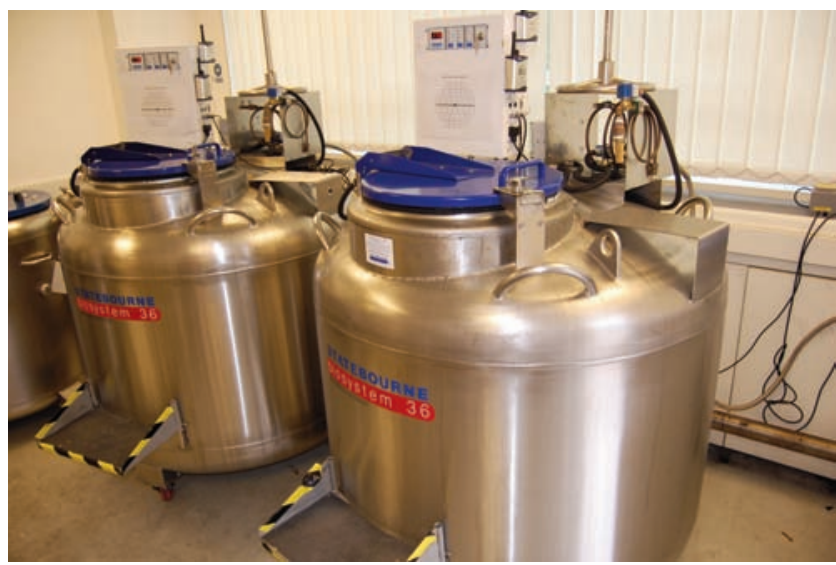

Figure 2. Cryo-storage in liquid nitrogen tanks [photo by kind permission of CABI Microbial Service (Egham, Surrey, UK)]. 
The effectiveness of microbial cryopreservation can be affected by several factors, for example, species, strain, growth phase and rate, growth medium composition, $\mathrm{pH}$, osmolarity and aeration, cell water content, lipid content and composition of the cells, density at freezing, composition of the freezing medium, cooling rate, temperature and duration of storage, warming rate and recovery medium. ${ }^{37}$ Furthermore, the freezing process has adverse effects on cells, since the removal of water during intracellular and extracellular freezing causes mechanical injury to the cell and changes the physical and chemical nature of the solutions within and around the cells. ${ }^{38,39}$ For this reason the rate of cooling is extremely significant and it should be controlled. In general, the best results for preservation of bacteria have been achieved with slow cooling at $1^{\circ} \mathrm{C} \mathrm{min}{ }^{-1}$ over the critical phase. ${ }^{27}$ This step can be controlled using a freezer which has an adjustable cooling rate. If a programmable control is not available, slow cooling can be obtained by placing the filled glass or plastic vials in a stainless steel pan at the bottom of a mechanical freezer at $-60^{\circ} \mathrm{C}$ for $1 \mathrm{~h}$ in order to achieve the rate of cooling of approximately $-1.5^{\circ} \mathrm{C} \mathrm{min}-1$. Then, if the frozen vials have to be stored in liquid or vapor phase of nitrogen, they can be plunged into a liquid-nitrogen bath for 5 min before transferring in liquid-nitrogen tank. ${ }^{28}$

Good results for microbial preservation can also be achieved using a commercially available container, Mr. Frosty System (Nalgene, Rochester, NY, USA). The container is filled with isopropyl alcohol at room temperature; this provides a slow rate of cooling of cells, close to the ideal of $-1^{\circ} \mathrm{C} \mathrm{min}^{-1}$, when placed at $-80^{\circ} \mathrm{C} .40$

It has been reported that the best recovery of the cryopreserved cultures is obtained by rapid thawing since slow warming may cause damage owing to the recrystallization of ice. A rapid rate of warming can be achieved by quickly immersing the frozen vials in a $37^{\circ} \mathrm{C}$ water bath with moderate agitation until all the ice melts. ${ }^{27,28}$

Several researchers have attempted to optimize cryopreservation processes through approaches that circumvent damage caused by water crystallization. Most improvements have been obtained using cryoprotective agents. Generally, glycerol and DMSO, which can penetrate the cells, contrary to other cryoprotectants, have proven to be the most effective for a wide range of bacteria, since they are able to provide both intracellular and extracellular protection against freezing. ${ }^{28}$

However, they should be used carefully because of their harmful toxicity at high concentrations. ${ }^{39} \mathrm{DMSO}$ and glycerol are routinely used at final concentration of $5 \%(\mathrm{v} / \mathrm{v})$ and $10 \%(\mathrm{v} / \mathrm{v})$, respectively in the proper suspending medium..$^{28}$ Nevertheless, higher concentrations of glycerol $(25 \% \mathrm{v} / \mathrm{v})$ have been reported to be successful for AAB cryopreservation. ${ }^{41,42}$ Recently, the stability of $A$. pasteurianus strain $\mathrm{AB} 0220$ over 9 years of preservation has been investigated. The phenotypic and genotypic data on the strain subcultures preserved for long time, at $-80^{\circ} \mathrm{C}$ with glycerol, have confirmed the suitability of the method for the authentic strain maintenance..$^{43}$ Nevertheless studies performed on the preservation of $G a$. xylinus have revealed the influence of cryoprotective agents on cellulose production. In particular the use of glycerol or skimmed milk was not recommended as both altered the structure of cellulose produced by $\mathrm{Ga}$. xylinus and influenced the bacterial metabolism. On the contrary, freezing in suspension with DSM0 guaranteed high survival rates and no determinable influence on cellulose structure and production. ${ }^{44}$

Validation of preservation techniques and quality control requirements In compliance with the Organization for Economic Co-operation and Development (OECD) best-practice guidelines (http//www.oecd.org/ dataoecd/7/13/38777417.pdf), microorganisms should be preserved preferably by two different methods and as master cell banks and as stocks for distribution. Where two distinct methods are not applicable to the biological material, cryopreserved stocks should be maintained in separate locations. To avoid the risk of losing significant strains, their deposit in a different collection is strongly advised, especially strains cited in publications, or, more generally, used in research so that they will be available to the international scientific community in both academic and industrial institutions. Moreover BRCs, among several services, can offer safe deposit of strains where their distribution is restricted at the discretion of the depositor. Furthermore culture collections recognized as International Depository Authority (IDA) can hold strains associated with patents under the Budapest Treaty. Culture collections can often apply specific protocols for cultures preservation, which are generally described in their own databases or reported in publications. However, validation of preservation techniques between collections is still not common and, for this reason, recent projects have taken this important aspect into consideration. ${ }^{45}$ Quality control of the preserved cultures is fundamental to validate the methodology used. BRCs are required to carry out quality controls on the received material, at least three occasions: upon receipt of the original material, after preservation of the first batch of samples, and after each subsequent new batch preservation. ${ }^{6}$ Specifically, quality control is performed in order to assess: viability of the culture on the medium/media recommended, purity, authenticity (conforms to the description provided by the depositor) and properties confirmed by phenotypic, metabolic and molecular characterization. ${ }^{6}$ Usually $16 \mathrm{~S}$ ribosomal RNA gene sequencing is helpful for bacteria species identity, however, for some AAB, which show high $16 \mathrm{~S}$ rRNA gene sequence similarities, other methods as multilocus sequence analysis can be more adequate for species differentiation in the family Acetobacteraceae. ${ }^{46}$ Moreover, several DNA fingerprinting methods, which may produce strain-specific banding patterns are more sensitive and suitable to detect any genetic drift, changes or deterioration during preservation. Examples for these methods are: amplified fragment-length polymorphism PCR (AFLP), pulsed field gel electrophoresis (PFGE), random amplified polymorphic DNA (RAPD) analysis, REP-PCR (repetitive extragenic palindromicPCR), ERIC-PCR (enterobacterial repetitive intergenic consensus sequences-PCR), BOX-PCR (derived from the boxA element), (GTG) ${ }_{5-}$ PCR and ribotyping. ${ }^{47}$ A major disadvantage of some of these fingerprint-based methods is that the results are often very difficult to compare when they have been obtained in different laboratories due to the lack of standardization. A key requirement of the techniques chosen is that they are reproducible. ${ }^{47,48}$ All the tests performed need to be made according to documented procedures and the results need to be recorded and retained for future reference.

\section{Databases and Biological Resources Centers networking}

Nowadays almost all BRCs have open catalogue databases available online with advanced search functionality. The actual level of detail contained within catalogues depends on the governance of the individual culture collection. Some catalogues only state minimal information on the strains e.g. strain number, species name and basic information about the depositor, whereas other BRCs offer detailed information on the origin of the culture, its history, its isolation, references to scientific literature and sequence information. ${ }^{49}$

In order to standardize and integrate the information among different culture collection databases, several initiatives have been designed from various BRCs. Among these, the Common Access to Biological Resources and Information (CABRI; http://www.cabri.org/ guidelines.html) offers world-wide access to catalogue databases of different types of organism, genetic materials and other biological in Europe and allows to simultaneous check on the availability of specific organisms or genetic resources. As a result, strains of organisms are supplied from member collections with traceability, conforming to national and international regulatory requirements. Another important initiative recently realized is the platform StrainInfonet 
(http:/www.straininfo.net). This provides essential support for the exchange of microbial information and meta-information by using a Microbial Common Language (MCL) ${ }^{49}$ Accordingly, strain designations, historic information on their deposit in BRCs, growth characteristics, genomics and other data, and relevant publications are shown to the user in an integrated way. This system has the potential to evolve into a global microbiological data-network of which the data can be directly used in scientific research, for example in combination with genomics for comparative studies..$^{50}$

Two main culture collection organizations, the World Federation for Culture Collections (WFCC) and the European Culture Collection Organization (ECCO), act as connection among collections and users, to coordinate activities as well as to exchange information and technologies. ${ }^{1}$

Currently, a small group of well-established European collections are working together in a European Union (EU)-sponsored project, the European Consortium of Microbial Resource Centers (EMbaRC; http://www.embarc.eu), aiming to improve, coordinate and validate collection delivery to European and international researchers. ${ }^{51}$ The goals are to ensure harmonization of the quality of microbial collections, taking the current OECD best-practice guidelines and emerging national quality standards for microbial resource centers to the international level. The consortium agrees that coordinated action is needed to store all relevant strains resulting from European research and that they need to work together to provide the capacity and expertise. ${ }^{51}$ Furthermore the Microbial Resources Research Infrastructure (MIRRI; http://www.mirri.org) has been recently established with the purpose to provide services facilitating access to high quality microorganisms, their derivatives and associated data for research, development and application. It connects resource holders with researchers and policy makers to deliver the resources and services more effectively and efficiently to meet the needs of innovation in biotechnology.

\section{The linkage between acetic acid collection and stake- holders}

The increased knowledge on AAB physiological, biochemical and genetic properties has encouraged advancement in biotechnology and innovative research methods. For instance, food technology has been largely advantaged by using $\mathrm{AAB}$ as functional starter cultures in acidification process. Culture collections are fundamental tools for selecting the ideal culture for any particular food application as they can provide a large pool of candidates to find the best one. In this way they can support biotechnology companies to develop new starters, with required performance parameters, which are superior to the ones found in nature, by using mutant selection and genetic engineering. The optimization of AAB starter cultures for vinegar production has been extensively investigated. ${ }^{52-54}$ Despite the several types of vinegar produced worldwide, selection criteria must always take in account the characteristics of the raw material, desired $\mathrm{AAB}$ metabolic activities, applied technology and desired characteristics of the final product. ${ }^{14,55}$ In addition to vinegars, $\mathrm{AAB}$ are also involved in the production of other fermented beverages and food products (e.g. nata, kombucha and cocoa). Generally, the advances in enzyme technology help to a greater extent in the search for a biocatalyst with the desired specificity for industrial needs. Therefore, the characterization of microorganisms which are able to thrive in peculiar or in extreme environments has received great attention as a valuable source for novel enzymes. ${ }^{56} \mathrm{AAB}$, being acidophilic microorganisms that grow in very specialized habitat might be of potential interest. Their extracellular enzymes might be highly stable at low $\mathrm{pH}$ and therefore could be particularly useful in acidic degradations and in the food industry. ${ }^{57}$ Other interesting biotechnological applications of some AAB strains regard to their ability to produce exopolysaccharides (EPS), which may have beneficial effects on human health. Bacterial EPS generally have unique rheological properties caused by their high purity and regular structure and, therefore, they can be used as thickening, gelling, or stabilizing agents in the food industry. ${ }^{58}$ Furthermore, bacterial cellulose has been extensively investigated for new materials useful for paper additives, diaphragm for headphones and artificial skin. ${ }^{59,60}$ Among AAB, strains belonging to Ga hansenii, Ga. intermedius and Ga. kombuchae have been reported to be capable of producing bacterial cellulose, however, Ga xylinus is certainly the most efficient producer. ${ }^{61-64}$

Concerning $G$. oxydans, it is mainly used by biopharmaceutical industry for the production of high-value organic chemicals e.g., precursors of vitamin C, precursors of miglitol, precursors of D-tagatose, dihydroxyacetone, D-gluconic acid, shikimate, L-ribulose and others. ${ }^{20,65,66}$ In the last decades, nitrogen-fixing AAB strains belonging to Gluconacetobacter, Acetobacter and Swaminathania genera have been considered valuable for agriculture as a tool for improving crop performance and environmental conditions, since they promote plant growth as well potentially reducing or avoiding the use of chemical fertilizers. ${ }^{67-69}$ Additionally, biosensor technology using AAB enzymes or whole-cells has been recently developed for testing and diagnosis in clinical, food, as well as environmental and agricultural fields. ${ }^{57}$

\section{Conclusions}

Acetic acid bacteria culture collection management requires dedication and expertise of the curators in different areas of microbial biology. The integration of sequence data with transcriptional and functional studies supplied from culture collections is essential to better define complex traits and optimize AAB biotechnological applications. Furthermore culture collections need to use high-level research and scientific services to meet the expectations of their customers and stakeholders in solving a variety of problems as well as exploiting the potential of AAB diversity. The essential role of culture collections and their significant contribution in $\mathrm{AAB}$ characterization, preservation as well as biotechnological application should be generally recognized and financially supported.

\section{References}

1. Smith D. Culture collections over the world. Int Microbiol 2003;6:95-100.

2. Cánovas M, Iborra JL. Culture collections and biochemistry. Int Microbiol 2003;6:105-12.

3. Snyder RW, Ruhe J, Kobrin S, et al. Asaia bogorensis peritonitis identified by $16 \mathrm{~S}$ ribosomal RNA sequence analysis in a patient receiving peritoneal dialysis. Am J Kidney Dis 2004;44:15-7.

4. Greenberg DE, Porcella SF, Stock F, et al. Granulibacter bethesdensis gen. nov., sp. nov., a distinctive pathogenic acetic acid bacterium in the family Acetobacteraceae. Int J Syst Evol Microbiol 2006;56:2609-16.

5. Alauzet C, Teyssier C, Jumas-Bilak E, et al. Gluconobacter as well as Asaia species, newly emerging opportunistic human pathogens among acetic acid bacteria. J Clin Microbiol 2010;48:3935-42.

6. Janssens D, Arahl DR, Bizet C, Garay E. The role of public biological resource centers in providing a basic infrastructure for microbial research. Res Microbiol 2010;161:422-9.

7. Gullo M, Caggia C, De Vero L, Giudici P. Characterization of acetic acid bacteria in traditional balsamic vinegar. Int $\mathrm{J}$ Food Microbiol 2006;106:209-12. 
8. De Vero L, Gala E, Gullo M, et al. Application of denaturing gel electrophoresis (DGGE) analysis to evaluate acetic acid bacteria in traditional balsamic vinegar. Food Microbiol 2006;23:809-13.

9. Wu J, Gullo M, Chen F, Giudici P. Diversity of Acetobacter pasteurianus strains isolated from solid-state fermentation of cereal vinegars. Current Microbiol 2010;60:280-6.

10. Millet $\mathrm{V}$, Lonvaud-Funel A. The viable but non-culturable state of wine microorganisms during storage. Lett Appl Microbiol 2000;30:136-41.

11. Mamlouk D, Hidalgo C, Torija MJ, Gullo M. Evaluation and optimisation of bacterial genomic DNA extraction for no-culture techniques applied to vinegars. Food Microbiol. 2011;28:1374-9

12. Sokollek J, Hammes WP. Description of a starter culture preparation for vinegar fermentation. Syst Appl Microbiol 1997;20:481-91.

13. Sengun IY, Karabiyikli S. Importance of acetic acid bacteria in food industry. Food Control 2011;22:647-56.

14. Gullo M, Giudici P. Acetic acid bacteria in traditional balsamic vinegar: phenotypic traits relevant for starter cultures selection. Int $\mathrm{J}$ Food Microbiol 2008;125:46-53.

15. Cleenwerck I, De Vos P. Polyphasic taxonomy of acetic acid bacteria: an overview of the currently applied methodology. Int J Food Microbiol 2008;125:2-14.

16. De Ley J, Gillis M, Swings J. Family VI. Acetobacteraceae. In: Krieg NR, Holt JG, eds. Bergey's manual of systematic bacteriology, vol. 1. Baltimore: Williams and Wilkins; 1984. pp 267-78.

17. Drysdale GS, Fleet GH. Acetic acid bacteria in winemaking: a review. Am J Enol Vitic 1988;39:143-54.

18. Seiskari P, Linko Y, Linko P. Continuous production of gluconic acid by immobilized Gluconobacter oxydans cell bioreactor. Appl Microbiol Biotechnol 1985;21:356-60.

19. Weenk G, Olijve W, Harder W. Ketogluconate formation by Gluconobacter species. Appl Microbiol Biotechnol 1984;20:400-5.

20. Deppenmeier U, Hoffmeister M, Prust C. Biochemistry and biotechnological applications of Gluconobacter strains. Appl Microbiol Biotechnol 2002;60:233-42.

21. Matsushita K, Toyama H, Adachi 0 . Respiratory chains and bioenergetics of acetic acid bacteria. Adv Microb Physiol 1994;36:247301.

22. Silberbach M, Maier B, Zimmermann M, Büchs J, Glucose oxidation by Gluconobacter oxydans: characterization in shaking-flasks, scale-up and optimisation of the $\mathrm{pH}$ profile. Appl Microbiol Biotechnol 2003;62:92-8.

23. Ohmori S, Uozumi T, Beppu T. Loss of acetic acid resistance and ethanol oxidizing ability in an Acetobacter strain. Agric Biol Chem 1982;46:381-9.

24. Takemura H, Horinouchi S, Beppu T. Novel insertion sequence IS1380 from Acetobacter pasteurianus is involved in loss of ethanol-oxidizing ability. J Bacteriol 1991;173:7070-6.

25. Kondo K, Horinouchi S. A new insertion sequence IS1452 from Acetobacter pasteurianus. Microbiology 1997;143:539-46.

26. Azuma Y, Hosoyama A, Matsutani M, et al. Whole-genome analyses reveal genetic instability of Acetobacter pasteurianus. Nucleic Acids Res 2009;37:5768-83.

27. Smith D. Culture collections and Biological Resource Centres (BRCs). In: Encyclopedia of industrial biotechnology: bioprocess, bioseparation, and cell technology. Flickinger MC, ed. Hoboken, NJ: Wiley \& Sons, Inc.; 2009. pp 1-19.

28. Gherna RL. 2010. Culture preservation. In: Encyclopedia of industrial biotechnology: bioprocess, bioseparation, and cell technology. Flickinger MC, ed. Hoboken, NJ: John Wiley \& Sons, Inc.; 2010. pp 1-18.

29. Rowe TWG, Snowman JW. Edwards freeze-drying handbook. Edwards high vacuum. Crawley: Sussex; 1978.

30. Ashwood-Smith MJ, Grant E. Mutation induction in bacteria by freeze-drying. Cryobiology 1976;13:206-13.

31. Morgan C, Herman N, White P, Vesey G. Preservation of microorganisms by drying. A review. J Microbiol Meth 2006;66:183-93.

32. Ndoye B, Cleenwerck I, Destain J, et al. Preservation of vinegar acetic acid bacteria. In: Solieri L, Giudici P, eds. Vinegars of the world. Milano: Springer-Verlag Italia; 2009. pp 61-71.

33. Nomura Y, Yamamoto M, Matsushita K, Kumagai H. Preparation and preservation of freeze-dried cells of acetic acid bacteria with aldehyde oxidase. Biosci Biotech Biochem 1998;62:1134-7.

34. Ndoye B, Cleenwerck L, Engelbeen K, et al. Acetobacter senegalensis sp. nov., a thermotolerant acetic acid bacterium isolated in Senegal (sub-Saharan Africa) from mango fruit (Mangifera indica L.). Int J Syst Evol Microbiol 2007;57:1576-81.

35. Smith D, Ryan MJ, Day JG, eds. The UK National Culture Collection (UKNCC) Biological Resource: properties, maintenance and management. London: UK National Culture Collection; 2001.

36. Stacey G. Fundamental issue for cell-line banks in biotechnology and regulatory affairs. In: Fuller BJ, Lane N, Benson EE, eds. Life in the frozen state. London: CRC Press; 2004. pp 437-52

37. Hubalek Z. Protectants used in the cryopreservation of microorganisms. Cryobiology 2003;46:205-29.

38. Mazur P. Physical and chemical basis of injury in single-celled micro-organisms subjected to freezing and thawing. In: H.T. Meryman, ed. Cryobiology. London: Academic Press; 1966. pp 231315 .

39. Moussa M, Dumont F, Perrier-Cornet JM, Gervais P. Cell inactivation and membrane damage after long-term treatments at sub-zero temperature in the supercooled and frozen states. Biotechnol Bioeng 2008;101:1245-55.

40. Simione FP. Cryopreservation manual. New York: Nalge Nunc International Corporation; 1998.

41. Cleenwerck I, Camu N, Engelbeen K, et al. Acetobacter ghanensis sp. nov., a novel acetic acid bacterium isolated from traditional heap fermentations of Ghanaian cocoa beans. Int J Syst Evol Microbiol 2007;57:1647-52.

42. Lefeber T, Janssens M, Camu N, De Vuyst L. Kinetic analysis of strains of lactic acid bacteria and acetic acid bacteria in cocoa pulp simulation media toward development of a starter culture for cocoa bean fermentation. Appl Environ Microbiol 2010;76:7708-16.

43. Gullo M, Mamlouk D, De Vero L, Giudici P. Acetobacter pasteurianus Strain AB0220: cultivability and phenotypic stability over 9 years of preservation. Curr Microbiol 2012;64:576-80.

44. Wiegand C, Klemm D. Influence of protective agents for preservation of Gluconacetobacter xylinus on its cellulose production. Cellulose 2006;13:485-92.

45. Smith D, Ryan M. Implementing best practices and validation of cryopreservation techniques for microorganisms. Sci World J 2012;80:56-9.

46. Cleenwerck I, De Vos P, De Vuyst L. Phylogeny and differentiation of species of the genus Gluconacetobacter and related taxa based on multilocus sequence analyses of housekeeping genes and reclassification of Acetobacter xylinus subsp. sucrofermentans as Gluconacetobacter sucrofermentans (Toyosaki et al. 1996) sp. nov., comb. nov. Int J Syst Evol Microbiol 2010;60:2277-83.

47. Tindall BJ, Rosselló-Móra R, Busse H-J, et al. Notes on the characterization of prokaryote strains for taxonomic purposes. Int J Syst Evol Microbiol 2010;60:249-66.

48. Smith D. Culture collections. Adv Appl Microbiol 2012;79:73-118.

49. Verslyppe B, Kottman R, De Smet W, et al. Microbiological Common Language (MCL): a standard for electronic information exchange in the Microbial Commons. Res Microbiol 2010;161:439-45.

50. Dijkshoorn L, De Vos P, Dedeurwaerdere T. Understanding patterns of use and scientific opportunities in the emerging global microbial commons. Res Microbiol 2010;161:407-13. 
51. Stackebrandt E. Diversification and focusing: strategies of microbial culture collections. Trends Microbiol 2010;18:283-7.

52. Sokollek SJ, Hertel C, Hammes WP. Cultivation and preservation of vinegar bacteria. J Biotech 1998,60:195-206.

53. Ndoye B, Lebecque S, Dubois-Dauphin R, et al. Thermoresistant properties of acetic acids bacteria isolated from tropical products of Sub-Saharan Africa and destined to industrial vinegar. Enzyme Microb Technol 2006;39:916-23.

54. Gullo M, De Vero L, Giudici P. Succession of selected strains of Acetobacter pasteurianus and other acetic acid bacteria in traditional balsamic vinegar. Appl Environ Microbiol 2009;75:2585-9.

55. Giudici P, Solieri L, Pulvirenti A et al. Strategies and perspectives for genetic improvement of wine yeasts. Appl Microbiol Biotechnol 2005;66:622-8.

56. Naessens M, Cerdobbel A, Soetaert W, Vandamme EJ. Leuconostoc dextransucrase and dextran: production, properties and applications. J Chem Technol Biotechnol 2005;80:845-60.

57. De Vero L, Gullo M, Giudici P. Acetic acid bacteria, biotechnological applications. In: Encyclopedia of industrial biotechnology: bioprocess, bioseparation, and cell technology. Flickinger MC, ed. . Hoboken, NJ: John Wiley \& Sons, Inc.; 2010. pp 1-17.

58. Kornmann H, Duboc P, Marison I, von Stockar U. Influence of nutritional factors on the nature, yield, and composition of exopolysaccharides produced by Gluconacetobacter xylinus I-2281. Appl Env Microbiol 2003;69:6091-8.

59. Vandamme EJ, De Baets S, Vanbaelen A, et al. Improved production of bacterial cellulose and its application potential. Polym Degrad Stabil 1998;59:93-9.

60. Jung JY, Khan T, Park JK, Chang HN. Production of bacterial cellu- lose by Gluconacetobacter hansenii using a novel bioreactor equipped with a spin filter. Korean J Chem Eng 2007;24:265-71.

61. Boesch C, Trcek J, Sievers M, Teuber M. Acetobacter intermedius sp. nov. Syst Appl Microbiol 1998;21:220-29.

62. Jia SR, Ou HY, Chen GB, et al. Cellulose production from Gluconobacter oxydans TQ-B2. Biotechnol Bioprocess Eng 2004;9:166-70.

63. Park JK, Khan T, Jung JY. Structural studies of the glucuronic acid oligomers produced by Gluconacetobacter hansenii strain. Carbohydr Polym 2006;63:482-6.

64. Dutta D, Gachhui R. Nitrogen-fixing and cellulose-producing Gluconacetobacter kombuchae sp. nov., isolated from Kombucha tea. Int J Syst Evol Microbiol 2007;57:353-7.

65. De Muynck C, Pereira CSS, Naessens M, et al. The genus Gluconobacter oxydans: Comprehensive overview of biochemistry and biotechnological applications. Crit Rev Biotechnol 2007;27: 147-71.

66. Stasiak L, Blazejak S. Acetic acid bacteria-perspectives of application in biotechnology- a review. Pol J Food Nutr Sci 2009;59:17-23.

67. Saravanan VS, Madhaiyan M, Osborne J, et al. Ecological occurrence of Gluconacetobacter diazotrophicus and nitrogen-fixing acetobacteraceae members: their possible role in plant growth promotion. Microb Ecol 2008;55:130-40.

68. Pedraza R0. Recent advances in nitrogen-fixing acetic acid bacteria. Int J Food Microbiol 2008;125:25-35.

69. Bertalan M, Albano R, Padua VD, et al. Complete genome sequence of the sugarcane nitrogen-fixing endophyte Gluconacetobacter diazotrophicus Pal5. BMC Genomics 2009;10:450. 